\title{
A AVALIAÇÃO E TRATAMENTO DO ERRO NO PROCESSO DE ENSINAGEM DE MATEMÁTICA POR BOLSISTAS PIBID DO IFCE CANINDÉ
}

\author{
Idelmar Gomes Ferreira, Ana Cláudia Gouveia de Sousa, \\ Luciana de Oliveira Souza Mendonça, Samara Moura Barreto de Abreu \\ Instituto Federal de Educação, Ciência e Tecnologia do Ceará (IFCE) \\ Campus de Canindé \\ <idelmargomes@live.com>, < anaclaudiaifce@gmail.com> \\ <professoralucianamendonca@gmail.com>,<samaraef@hotmail.com>
}

DOI: $10.21439 /$ conexoes.v9i4.987

\begin{abstract}
Resumo. O presente estudo objetiva analisar como os erros apresentados em uma avaliação são percebidos e sua relação com a ensinagem na formação de licenciandos em Matemática no contexto do PIBID, tendo como referenciais os trabalhos de Philippe Perrenoud, Jussara Hoffmann, Cipriano Carlos Luckesi, Léa Depresbiteris, Neuza Bertoni Pinto e Léa Anastasiou. A pesquisa é do tipo exploratória, de campo, matizada pela abordagem qualitativa. O instrumento de coleta foi um teste denominado Teste de Concepções de Erro para Professores de Matemática, elaborado por Ferreira e Mendonça (2015), respectivamente Bolsista (ID) e coordenadora do Pibid de Matematica do IFCE Canindé. Os dados revelam que houve um alto índice de variabilidade na pontuação de cada questão do Teste e que cada participante teve uma percepção diferente sobre os erros construtivos apresentados. Isso indica que o ato de avaliar não é tarefa fácil e sim subjetiva, pois cada participante atribuiu uma nota diferente. Entende-se que a maturação sobre as concepções de avaliação e erro são oportunizadas pela reflexão sobre a prática, para a construção da profissão docente no contexto da práxis. Pretende-se com esse trabalho contribuir para uma discussão mais aprofundada sobre a avaliação e erro no contexto da formação inicial e do Projeto de Iniciação a Docência tendo em vista as diferentes concepções reveladas, com diferentes critérios avaliativos, que nem sempre tem o erro como parte do processo da aprendizagem matemática.
\end{abstract}

Palavras-chaves: Ensinagem. Matemática. Pibid. Erro. Avaliação.

\begin{abstract}
This study aims to analyze how the errors presented in an evaluation are perceived and their relation with the teaching in the qualification of Mathematics Graduation students in PIBID context, having as references the works of Philippe Perrenoud, Jussara Hoffmann, Cipriano Carlos Luckesi, Léa Depresbiteris, Neuza Bertoni Pinto and Léa Anastasiou. The research is of the type exploratory, of field, more guided by the qualitative approach. The instrument of data collecting was a test called Teste de Concepções de Erro para Professores de Matemática, ellaborated by Ferreira e Mendonça (2015) the scholarship student (ID) and the PIBID coordinator of Mathematics from IFCE Canindé. Data reveals that there was a high degree of variability regarding the grading of each question of the Test and that each participant had a different understanding of the constructive errors presented. This indicates that the act of evaluating is not an easy and but rather subjective task, as each participant assigns a different note. We understand that the maturation about the evaluation and error conceptions are enabled by reflexion about the practice,but even raised in the apprehension of the lecturer's profession's characteristics in the context of praxis. With this work, it is intended to contribute to a deeper discussion about evaluation and error in the context of the initial qualification and of the Projeto de Iniciação a Docência, bearing in mind the different conceptions revealed, with different evaluation standards, that show the error is not always part of the process of learning Mathematics.
\end{abstract}

Keywords: Teaching. Mathematics. Pibid. Error. Evaluation. 


\section{INTRODUÇÃO}

O processo de ensinagem da Matemática tem sido um grande desafio devido a sua complexidade, e existem nesse processo diferentes concepções de ensino e de aprendizagem que nem sempre são coerentes com o discurso e a prática de ensinar. Dentre as diversas concepções de aprendizagem, esse projeto de pesquisa se insere numa perspectiva de tornar construtivo o ato de ensinar e avaliar.

No contexto da avaliação consideramos erro construtivo os erros dos educandos como parte do processo de aprender, e estes não podem ser desconsiderados e sim trabalhados para que se possa, a partir desses erros, construir ou reconstruir o saber necessário, não só na Matemática, mas também em todas as outras áreas. Para este trabalho a avaliação da aprendizagem que consideramos é uma avaliação inclusiva, dinâmica e construtiva, que se diferencia dos exames, que são excludentes, não são construtivos, e sim classificatórios.

Partimos do conceito de ensinagem referendado por Anastasiou (2003) entendendo dialeticamente,

Como uma prática social complexa efetivada entre os sujeitos, professor e aluno, englobando tanto a ação de ensinar quanto a de apreender, em um processo contratual, de parceria deliberada e consciente para o enfrentamento na construção do conhecimento escolar (ANASTASIOU 2003 p. 15).

Ao mesmo tempo, consideramos os estudos de Garnica (2008) que indica que as concepções, por não serem estáticas, envolvem crenças, percepções, juízos, experiências prévias, a partir dos quais nos julgamos aptos a agir. Identificamos na ação efetiva que as práticas podem ser desveladas e não através dos discursos que promovemos sobre elas, deixando claro que "concepções são, portanto, suportes para a ação. Mantendose relativamente estáveis, as concepções criam em nós alguns hábitos, algumas formas de intervenção que julgamos seguras" (GARNICA, 2008, p. 499).

Em nossas primeiras observações e estudos sobre os processos avaliativos, no âmbito da formação dos licenciandos com destaque para experiência vivida nos Estágios Supervisionados e no Programa Institucional de Bolsas de Iniciação a docência (PIBID) na relação docência e discência, foi possível percebermos que a literatura aponta que na prática docente existe uma grande distorção no processo de avaliar, sendo mais um ato de julgar o educando pelos erros do que avaliar sua aprendizagem, visto que, a partir de testes e provas, se tem tentado medir a aprendizagem do educando, punindoo pelo seu erro, não sendo feito uma reflexão junto ao educando do que lhe conduziu ao erro.
Além disso, muitas vezes, existe ainda na prática pedagógica a exposição dos erros dos educandos de uma forma punitiva, que tem causado constrangimentos aos mesmos ao expor publicamente na sala de aula o que eles não aprenderam, sem muitas vezes se preocuparem em quem aprendeu, sendo esta uma forma de punição, levando-os, mesmo sem a intenção, a serem ridicularizados, como afirma Romano (1994),

\section{[...] O professor faz perguntas aos alunos, não porque está interessado em saber quem aprendeu o que foi en- sinado, mas para "verificar" quem não aprendeu, sem se dar conta de estar expondo publicamente aos colegas da classe a fragilidade daquele que não sabe responder. O "forte" na lição é elogiado e o "fraco" é ridiculari- zado, ainda que não explicitamente. A vergonha funci- ona como "lição" para que da próxima vez se empenhe mais ou preste mais atenção (ROMANO 1994 p. 4).}

Em outro aspecto o erro é visto pelo professor como um indicador do mau desempenho do educando, sem jamais ser utilizado para produzir novas dimensões de ensino. Sendo que, para Pinto (2000) o ensino é permeado por uma pedagogia da resposta, em que o erro é o sintoma visível do fracasso do educando, assim como o acerto é o sinal mais evidente de seu sucesso.

Na concepção tradicional de educação escolar, a resposta incorreta é ignorada e apagada, e o professor é considerado como detentor do saber, enquanto que deveria atuar na raiz dos erros e no processo que produz esses erros, evidenciando uma postura de investigador e refletir até mesmo sobre sua prática pedagógica.

Os erros observados não têm sido problematizados de forma que possam servir ou propiciar uma discussão, um diálogo em torno da produção do conhecimento matemático. Segundo Pinto (2000, p. 12), "a não concretização desse diálogo na sua plenitude empobrece a utilização didática do erro, prejudicando significativamente, o desempenho dos alunos".

É necessário ressaltar que explicitar o erro sem apreciar quais fatores induzem o educando a ele, é desconsiderar múltiplas situações que possibilitam ao educador se confrontar com os conhecimentos prévios do educando, trabalhar com a revisão de conceitos e também o exercício de argumentação.

O presente trabalho se justifica, portanto, pelo fato da avaliação e tratamento do erro articulada à ensinagem, ser de grande relevância para nossa educação e ainda ser um tema pouco pesquisado na Educação Matemática, como pudemos verificar através da realização de um levantamento bibliográfico feito em fevereiro de 2015 no Portal Periódicos da Coordenação de Aperfeiçoamento de Pessoal de Nível Superior (CAPES), somente de Teses e Dissertações entre 2005 - 2015, que tivesse uma relação entre concepções de professores, 
avaliação e erro. E encontramos algumas teses e dissertações referentes às concepções de professores em relação ao processo de ensino-aprendizagem, avaliação e erro. Trazemos a seguir os títulos e os objetivos de cada trabalho, no Quadro 1 .

Quadro 1: Trabalhos entre 2005 - 2015

\begin{tabular}{|c|c|}
\hline AUTORES /ANO & TITULOS E OBJETIVOS \\
\hline \multirow[b]{2}{*}{$\begin{array}{l}\text { BERTI, Nivia Martins } \\
\text { (2007) }\end{array}$} & $\begin{array}{l}\text { Titulo: A análise do erro sob a perspectiva didático-pedagógica no ensino- } \\
\text { aprendizagem da matemática: um estudo de caso na } 5^{2} \text { série. }\end{array}$ \\
\hline & $\begin{array}{l}\text { Objetivo: Investigar a compreensão que os alunos possuem sobre seus } \\
\text { próprios erros e as relaçós destes com o processo de ensino- } \\
\text { aprendizagem e, também, identificar e descrever passagens de aula e } \\
\text { formas de tratamento pedagógico dado aos erros e estrategias dos alunos } \\
\text { que contribuam para o desenvolvimento da operatividade e da autonomia } \\
\text { no processo ensino-aprendizagem, por meio da co-operaçąa. }\end{array}$ \\
\hline \multirow[b]{2}{*}{$\begin{array}{l}\text { SANTIAGO, Edina } \\
\text { Coleta }(2007) \text {. }\end{array}$} & $\begin{array}{l}\text { Titulo: Concepp̧ões e práticas avaliativas de professores formadores e de } \\
\text { acadêmicos futuros professores, em curso de licenciatura em matemática. }\end{array}$ \\
\hline & $\begin{array}{l}\text { Objetivo: compreender como ocorre o processo de desenvolvimento das } \\
\text { concepçôes e práticas avaliativas na formação dos professores de } \\
\text { matemática; de conhecer as tendências dos pesquisados sobre avaliação, } \\
\text { de enfocar a ideia do subjetivo, passivel de expor sensações e opiniões, e } \\
\text { qual o sentido que foi dado ao assunto em estudo. }\end{array}$ \\
\hline \multirow{2}{*}{$\begin{array}{l}\text { BOCALON, Graciela } \\
\text { Zanchet (2008) }\end{array}$} & $\begin{array}{l}\text { Titulo: } \mathrm{O} \text { erro na aprendizagem de frações no ensino fundamental: } \\
\text { concepções docentes. }\end{array}$ \\
\hline & $\begin{array}{l}\text { Objetivo: Investigar as concep̧ões de erros presentes nas práticas } \\
\text { pedagógicas de professores que ensinam matemática nas } 5^{2} \text { séries do } \\
\text { ensino fundamental na avaliação da aprendizagem. }\end{array}$ \\
\hline \multirow[b]{2}{*}{$\begin{array}{l}\text { TANUS, Vera Lúcia } \\
\text { Fernandes Aragão } \\
\text { (2008) }\end{array}$} & $\begin{array}{l}\text { Titulo: O tratamento dado ao erro no processo ensino-aprendizagem da } \\
\text { Matemática, por professores do Ensino Fundamental: encontros e } \\
\text { desencontros entre concepçôes e práticas. }\end{array}$ \\
\hline & $\begin{array}{l}\text { Objetivo: Investigar a relação existente entre as concepções de } \\
\text { conhecimento matemático, aprendizagem, avaliação e a prática docente e } \\
\text { interpretar se o tratamento dado ao erro no processo de ensino- } \\
\text { aprendizagem da Matemática está a elas vinculado. }\end{array}$ \\
\hline \multirow{2}{*}{$\begin{array}{l}\text { PAULA, Jacqueline } \\
\text { Borges de (2010) }\end{array}$} & $\begin{array}{l}\text { Título: A avaliação em matemática: concepções de ensino, de } \\
\text { aprendizagem e de avaliação dos professores e presentes nos relatórios } \\
\text { descritivos avaliativos da aprendizagem dos seus alunos. }\end{array}$ \\
\hline & $\begin{array}{l}\text { Objetivo: Investigar as concepcões de ensino, de aprendizagem e de de } \\
\text { avaliação em Matemática presentes nas falas dos professores do } 6^{\circ} \text { ano do do } \\
\text { Ensino Fundamental e nos relatórios descritivos avaliativos da } \\
\text { aprendizagem dos seus alunos. }\end{array}$ \\
\hline \multirow{2}{*}{$\begin{array}{l}\text { SIBILA, Miriam } \\
\text { Cristina Cavenaghi } \\
\text { (2012) }\end{array}$} & Titulo: O erro e a avaliação da aprendizagem: concepções de professores. \\
\hline & $\begin{array}{l}\text { Objetivo: Analisar as relações, possiveis de serem estabelecidas, entre } \\
\text { avaliação da aprendizagem, promocãa de feedback e regulação do erro, } \\
\text { intentando aclarar correspondências e aproximaçōes com seus } \\
\text { sentimentos frente ao erro. }\end{array}$ \\
\hline
\end{tabular}

Fonte: <http://www.periodicos.capes.gov.br>/ Acesso em fev. de 2015.

Como podemos perceber o assunto que aborda a questão das concepções de professores em relação ao processo de ensino-aprendizagem, avaliação e erro, apesar de se configurar num cenário de extrema relevância dentro do contexto da prática docente ainda existem poucos trabalhos sobre essa temática, principalmente em relação às concepções de avaliação e erro no contexto da Educação Matemática, por esse motivo, essa temática se torna tão relevante e a inexistência de um estudo local sobre o assunto também nos instiga para esta pesquisa.

No entanto, a partir das observações e estudos que fizemos sobre essa temática detectamos algumas pes- quisas realizadas que têm nos mostrado uma preocupação com os métodos de avaliações em relação aos educandos, com isso, surge a necessidade de se fazer estudos mais aprofundados sobre essa questão.

E em relação aos erros cometidos no processo de aprender por parte dos educandos, na busca de novos conhecimentos, é que os professores de matemática precisam se interrogar: Como e em que medida o erro do educando pode ser aproveitado na construção de sua aprendizagem matemática na perspectiva dos futuros professores? Sendo essa interrogação o assunto pesquisado neste trabalho.

Neste contexto, nos instigou investigar como os erros cometidos pelos educandos eram percebidos pelos licenciandos em Matemática que são bolsistas do PIBID de matemática do IFCE Campus Canindé. Acreditamos que tudo depende das percepções de ensinoaprendizagem e avaliação que os futuros professores possuem.

A partir dessa problematização, a pesquisa buscou atingir alguns objetivos. $\mathrm{O}$ objetivo geral, portanto, consiste em analisar como os erros apresentados em uma avaliação são percebidos e sua relação com a ensinagem na formação de licenciandos em Matemática no contexto do PIBID. Os objetivos específicos constituem-se em:

a) Verificar, através de um teste, como os participantes do PIBID avaliam os erros dos seus educandos.

b) Identificar as percepções de ensino-aprendizagem e avaliação dos licenciandos em Matemática e atuantes no PIBID em relação aos erros cometidos por seus educandos.

c) Discutir a relação entre concepções de ensinoaprendizagem, avaliação e erro, tendo como base as análises feitas nesta pesquisa.

Assim, destacamos como relevante a importância da compreensão sobre avaliação e o tratamento do erro na formação docente, e muito mais na formação inicial, abrindo perspectivas de continuidade para investigações acerca das próprias ações vivenciadas no dia a dia em sala de aula.

E para obtermos um trabalho que possa proporcionar fazermos uma análise das concepções dos bolsistas do PIBID sobre esse assunto e elucidar a reflexão sobre o processo de avaliar e o tratamento do erro na aprendizagem de Matemática, utilizamos a aplicação de um teste elaborado por parte dos autores desse artigo, contendo erros conceituais, para um grupo de estudantes de Licenciatura em Matemática que atuam no PIBID, corrigirem pontuando esses erros e justificando sua pontu- 
ação, como instrumento de coleta de dados. Esse teste foi denominado como Teste de Concepções de Avaliação e Erro para Professores de Matemática.

A escolha do público de futuros professores, todos licenciandos em Matemática, se deu pelo fato de já atuarem em sala de aula nas ações do PIBID dentro das escolas parceiras do projeto, e a partir dessa realidade nos despertou o interesse de sabermos que percepção têm esses futuros professores em relação ao processo de ensino-aprendizagem e avaliação de seus alunos, a partir das primeiras experiências como docentes.

O PIBID tem um caráter formativo e tem como objetivos: incentivar a formação docente; valorizar o magistério; inserir os licenciandos no cotidiano das escolas públicas de educação básica, proporcionando-lhes oportunidades de criação e participação em experiências metodológicas, tecnológicas e práticas docentes de caráter inovador e interdisciplinar buscando superar os problemas identificados no processo de ensinoaprendizagem; e contribuir para a articulação entre teoria e prática necessárias à formação dos docentes, elevando a qualidade das ações acadêmicas nos cursos de licenciatura 1 .

A partir da análise dos dados obtidos pela aplicação do teste que envolveu diferentes tipos de erros construtivos, para ver como os participantes da pesquisa avaliariam na prática, fizemos uma análise no intuito de responder e identificar as diferentes percepções de ensinoaprendizagem, de avaliação e erro do educando, tendo como referencial o erro numa perspectiva construtiva.

Com esse trabalho pretendemos subsidiar e aprofundar uma discussão sobre como a avaliação e o erro são concebidos pelos futuros professores de Matemática e qual a importância dessas percepções no processo de ensino e aprendizagem de Matemática, bem como o maior estudo teórico-prático do ato de avaliar nos cursos de formação inicial, bem como no contexto dos projetos do PIBID.

Pois essa pesquisa se insere no contexto de como se aprende a Matemática e de como esta é ensinada, e isso passa pelas percepções de professores e futuros professores, trazendo como alvo a avaliação que está ligada estreitada a relação de ensino aprendizagem. E para este trabalho trazemos também a ideia do erro do educando como construção do conhecimento em Matemática.

Para melhor entendermos sobre avaliação da aprendizagem, que é um dos aspectos mais complexos e polêmicos em Educação, refletiremos um pouco sobre o histórico da avaliação e seus conceitos. Mas, antes se

${ }^{1}$ Para mais informações sobre o que é o PIBIB, acesse o site: <http://www.capes.gov.br/educacao-basica/capespibid> faz necessário entendermos os conceitos de ensinar e de aprender, para depois discutirmos o processo de avaliação da aprendizagem.

Nas concepções de ensino e de aprendizagem, tanto para a pedagogia tradicional quanto para a tecnicista, "[...] aprender é sinônimo de memorizar, sendo que o ensinar significa verbalizar conteúdos e tomar a lição do dia." (GONÇALVES; LARCHERT, 2011, p. 17-18). Portanto, nessa visão tradicional e tecnicista o ensino e a aprendizagem são processos paralelos, e não estão estreitamente relacionados.

Já sob a visão da pedagogia progressista,

\section{[...] aprender é um processo complexo, reflexivo e ativo que se efetiva durante as experiências de assimilação de conhecimentos ou aquisição de competências e habili- dades. Portanto o ensino é a orientação, o acompanha- mento da aprendizagem do aluno (GONÇALVES; LAR- CHERT 2011 p. 18).}

Com relação à avaliação, três autores, reconhecidos e influentes em estudos sobre a temática da avaliação no Brasil no estreitamento de uma visão mais progressista sobre avaliação são: Luckesi (1998), Perrenoud (1999), Hoffman (1993).

Luckesi (1998) afirma que a avaliação da aprendizagem é uma prática de investigação do professor, cujo sentido é intervir na busca de melhores resultados do processo de aprendizagem, dentro da sala de aula, sendo a avaliação um juízo de qualidade sobre dados relevantes para uma tomada de decisão. Mas, a função que a prática da avaliação escolar tem estipulado é de avaliar a classificação e não o diagnóstico como deveria ser, como afirma Luckesi (1998):

\begin{abstract}
A atual prática da avaliação escolar estipulou como função do ato de avaliar a classificação e não o diagnóstico, como deveria ser constitutivamente. Ou seja, o julgamento de valor, que teria a função de possibilitar uma nova tomada de decisão sobre o objeto avaliado, passa a ter a função estática de classificar um objeto ou um ser humano histórico num padrão definitivamente determinado (LUCKESI 1998 p. 34).
\end{abstract}

A partir das observações feitas por Luckesi (1998), ele afirma que a prática educacional no Brasil opera quase sempre como verificação e não como avaliação, e por isso tem se utilizado o processo de aferição da aprendizagem de forma negativa, pois tem servido para desenvolver o medo nas crianças e nos jovens devido à constante "ameaça" de reprovação. Nesse aspecto o erro do educando nunca foi bem visto dentro da sala de aula pelos professores, sendo que,

\footnotetext{
A ideia e a prática do castigo decorrem da concepção de que as condutas de um sujeito - aqui, no caso, o aluno - que não correspondem a um determinado padrão preestabelecido, merecem ser castigados, a fim de que ele
} 
"pague" por seu erro e "aprenda" a assumir a conduta que seria correta (LUCKESI 1998, p. 52).

Contudo, essa concepção precisa ser repensada pelos professores e a partir daí ver o erro do educando numa perspectiva mais construtiva. Para Luckesi (1998),

[...] o erro poderia ser visto como fonte de virtude, ou seja, de crescimento. O que implicaria estar aberto a observar o acontecimento como acontecimento, não como erro; observar o fato sem preconceito, para dele retirar os benefícios possíveis. Uma conduta, em princípio, é somente uma conduta, um fato; ela só pode ser qualificada como erro a partir de determinados padrões de julgamento (LUCKESI 1998 p. 53-54).

Para Hoffman (1993), a avaliação é própria e inseparável da aprendizagem enquanto compreendida como problematização, questionamento e reflexão sobre a ação. Sendo a avaliação uma reflexão transformada em ação, e que estimule para novas reflexões. Ainda de acordo com Hoffmann (2013), o professor juntamente com o educando devem buscar coordenar seus pontos de vista, trocar ideias reorganizando-as. Nesse caso a postura do professor frente às alternativas de solução construídas pelos educandos deve estar necessariamente comprometida com uma concepção de erro construtivo.

E para Perrenoud (1999), a avaliação da aprendizagem é um processo mediador na construção do currículo e se depara estreitamente relacionada com a gestão da aprendizagem dos educandos. No entanto, devido à grande quantidade de estudos em diversos contextos educacionais sobre avaliação do processo de ensino aprendizagem, buscaremos restringir o foco no que diz respeito a essa temática, incluindo o erro do educando como construção do conhecimento em Matemática dentro do processo avaliativo do ensino aprendizagem. Pois, ao partir do princípio de que o erro é considerado como uma fonte de aprendizagem, neste sentido, ele pode promover ao educando importantes descobertas e desafios que o estimulará no prazer do saber e do fazer.

Segundo Sperafico e Golbert (2011), o erro tem um importante papel no processo de ensino, pois além de identificar os obstáculos que dificultam o educando a progredir em relação a um conteúdo ajuda o educador a formular diferentes estratégias para contorná-los. E para sair de um ensino mecanizado, muitas vezes desprovido de significado para o educando, é preciso possibilitar uma construção significativa dos conhecimentos matemáticos estimulando-os, a partir do erro, que é comum no processo da aprendizagem, discutir e explorar estes erros para facilitar a compreensão de ideias essenciais para a construção desse conhecimento. Conhecer o erro e analisá-lo ajuda não só o docente, mas também o educando a trabalharem em conjunto utilizando-se de diferentes práticas e métodos educativos. De acordo com os Parâmetros Curriculares Nacionais (PCN) de Matemática,

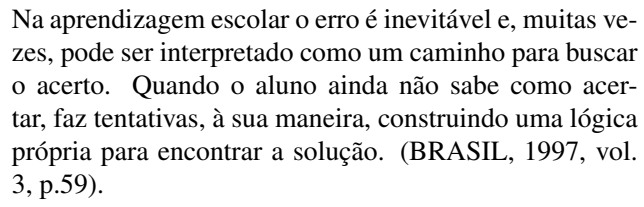

Apesar dos erros cometidos, a construção do conhecimento se faz evidente no processo de aprendizagem, pois não é somente o acerto que define sua aprendizagem, o errar também faz parte. Como se refere Perrenoud (2000), "todos tenham direito de errar para evoluir. Ninguém aprende sem errar. Errando, reflete-se mais sobre o problema e sobre as ações usadas para resolvê-lo".

Porém, ainda é muito presente nas nossas escolas de Educação Básica, a prática de exames de forma semelhante ao que acontecia em épocas atrás, já citadas neste trabalho. Usualmente a escola considera que avaliar tem o significado de "cobrar conceitos", "definições", "fórmulas e teoremas" já prontos, vistos em sala de aula. Dessa forma, podemos perceber que essas práticas ainda tradicionais sobre avaliação estão diretamente ligadas às concepções que os professores têm em relação às abordagens do processo de ensino-aprendizagem

\section{PROCEDIMENTOS METODOLÓGICOS}

\subsection{Tipo do Estudo}

Os métodos que traçamos no intuito de alcançar os objetivos determinados decorrem da perspectiva de buscar uma visão diferente por parte dos professores em relação à avaliação do educando considerando os erros que eles cometem dentro do processo de ensino e aprendizagem.

Por esse motivo, nossa pesquisa é do tipo exploratório, de campo, com abordagem qualitativa, pois, como destaca Bogdan e Biklen (1982 apud LÜDKE; ANDRÉ, 2013) a pesquisa qualitativa "envolve a obtenção de dados descritivos, obtidos no contato direto do pesquisador com a situação estudada, enfatiza mais o processo do que o produto e se preocupa em retratar a perspectiva dos participantes".

\subsection{Participantes da Pesquisa}

O público escolhido para nossa pesquisa são doze alunos do curso de Licenciatura em Matemática do oitavo semestre, bolsistas do PIBID do Instituto Federal 
de Educação, Ciência e Tecnologia do Ceará - Campus Canindé. Esse público fez parte da pesquisa pelo fato de querermos investigar qual é a visão desses futuros professores em relação as suas percepções sobre ensino-aprendizagem, avaliação e os erros dos educandos, como eles pensam a respeito disso.

Esses sujeitos foram escolhidos porque já atuam em atividades docentes como bolsistas a mais de dois anos, sendo os licenciandos e bolsistas PIBID com maior tempo de atuação, e em breve como professores devidamente licenciados, por isso a importância deles nesta pesquisa, para que pudéssemos fazer análises mais detalhadas da visão desses futuros docentes em relação ao ensino-aprendizagem e avaliação, quando se depararem com os erros dos educandos.

\subsection{Procedimentos de Coleta de Dados}

Os sujeitos da pesquisa fizeram a correção de uma avaliação que denominamos Teste de Concepções de Avaliação e Erro para Professores de Matemática elaborado por Ferreira e Mendonça (2015), respectivamente Bolsista (ID) e coordenadora do Pibid de Matemática do IFCE Canindé, contendo erros construtivos em que além da pontuação deveriam justificar a pontuação relativa aos erros.

A partir da análise dos dados obtidos pela aplicação do teste que envolveu diferentes tipos de erros construtivos para ver como os participantes da pesquisa avaliaram na prática, fizemos uma análise a fim de triangular os diferentes dados obtidos nos diferentes instrumentos de cada sujeito no intuito de responder e identificar as diferentes concepções de ensino-aprendizagem, de avaliação e erro do educando, e analisamos essas percepções tanto em relação à coerência entre elas, quanto às possíveis diferenças, tendo como referencial o erro numa perspectiva mais construtiva.

A partir desta aplicação fizemos uma análise de forma detalhada no intuito de destacarmos a coerência ou não das concepções de ensino, aprendizagem e avaliação, e assim pudemos apresentar uma relevante discussão para muitos docentes que enfrentam essas dificuldades para fazerem uma avaliação coerente com a aprendizagem de seus educandos.

\section{DISCUSSÃO E ANÁLISE DOS DADOS}

As cinco questões analisadas envolvem respectivamente medida de perímetro, cálculo de área, regularidade de uma sequência, cálculo de altura máxima e regra de três inversamente proporcional, com nível mais voltado para os anos finais do Ensino Fundamental. E em cada questão aferimos uma resposta contendo erros construtivos de forma proposital, para que os sujeitos da pesquisa pudessem avaliar dando uma pontuação e depois justificassem a pontuação relativa aos erros.

$\mathrm{Na}$ análise das notas e justificativas dadas às resoluções das questões, seguimos a ordem em que elas apareceram no teste. Nomeamos os participantes por P1, P2, P3, P4, P5, P6, P7, P8, P9, P10, P11 e P12 quando forem citados no texto da análise. Passamos, agora, à análise das notas e justificativas dadas a cada questão.

\subsection{Análise da Questão 1}

A primeira questão aborda um problema do cotidiano, que diz o seguinte: Deseja-se construir numa cidade uma praça com o mesmo formato e medidas indicados na figura 1 abaixo. Para esta construção, calcule quantos metros de tapumes na altura de $1 \mathrm{~m}$ deverá ser gasto para cercar todo o perímetro da praça?
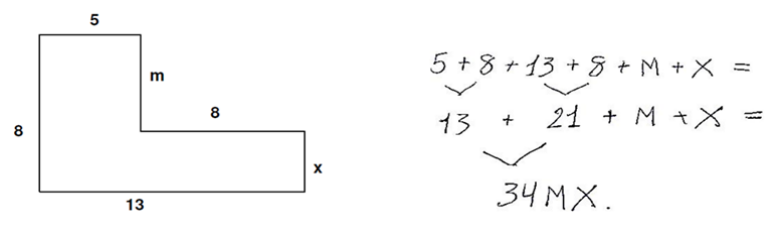

Figura 1: Representação da questão e resolução do aluno.

Como vimos, o objetivo dessa questão é encontrar a quantidade de tapumes em metros para cercar todo o perímetro da praça, mas a resposta que deixamos, apresenta de forma proposital um erro construtivo, com relação à dificuldade de um educando em aceitar uma soma com representações algébricas. E o intuito é saber como que os futuros professores, bolsistas do PIBID fariam essa avaliação, aplicando uma nota e justificando-as.

Apenas 05 (cinco) participantes correspondentes a $41,67 \%$ perceberam o tipo de erro e justificaram suas notas de forma coerente com o erro do educando na questão, que pedia para representar o perímetro de uma figura que tem a medida de alguns lados determinada, e de outros, apenas a representação algébrica, e que o educando errou no fechamento da questão. Onde ele teve dificuldade de aceitar $34+m+x$ como resposta válida.

Nessa questão, uma justificativa bem ilustrativa da percepção do erro proposital que colocamos foi a do participante $\mathrm{P} 7$ ao argumentar que, O aluno conseguiu demonstrar a competência em relação
à compreensão de perímetro, porém demonstrou não ter
bem formado o conceito de soma e confunde esse com
uma multiplicação. Em outras palavras, o aluno conse-
guiu iniciar a resolução corretamente mais cometeu uma 
grande falha em relação à conclusão da resolução. (Participante P7)

Outros 05 (cinco) participantes o que equivale a $41,67 \%$ justificaram suas notas de forma desconexa com a questão e com a resolução do educando.

Uma das justificativas dadas que mostra essa desconexão com a resolução foi a do participante P11, ao argumentar que "o aluno deveria ter primeiro encontrado os valores de $m$ e de $x$, para só então ter tentado resolver o problema"(P11). Mas, sabemos que os valores dessas variáveis ficariam mesmo em termos de $m$ e $x$, não podendo ser encontrado um valor exato.

Dois participantes, ou seja, $16,66 \%$ justificaram suas notas desconsiderando totalmente a resolução do educando. E podemos perceber isso na justificativa dada pelo participante $\mathrm{P} 4$, ao dizer que "o aluno não compreendeu o que a questão está pedindo, neste caso podemos avaliar que o mesmo compreende o conceito de perímetro"(P4). Mas pela resolução dada pelo educando, é possível perceber que ele compreendeu a questão, e começou a resolver corretamente, mostrando também que compreende o conceito de perímetro, e errou apenas no final da resolução.

Calculando o coeficiente de variação $(\mathrm{CV})$ entre as notas dadas na questão 1 obtivemos um coeficiente de variação igual a $80,13 \%$ indicando uma alta variabilidade das notas dadas pelos participantes da pesquisa.

\subsection{Análise da Questão 2}

A segunda questão trazia o seguinte problema: Para construir uma escola é feito o esboço da área do terreno no qual estão indicadas as medidas dos seus lados e tem a forma da Figura 2 Com essas medidas, qual a área total desse terreno?

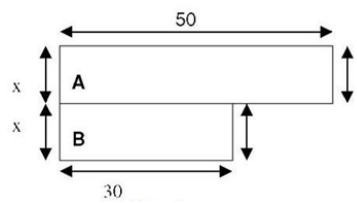

$$
2 x \cdot 50-(x \cdot 10)
$$

Figura 2: Representação da questão e resolução do aluno.

O problema exposto tem como objetivo encontrar uma expressão que represente a área da figura representada, e de forma proposital, apresentamos uma possível resolução de um educando que contém um erro construtivo. Novamente, o intuito é saber como que os futuros professores, bolsistas do PIBID fariam essa avaliação, aplicando uma nota e justificando-as.
A partir da resolução da questão que propõe a representação algébrica da área de uma figura, apenas seis (06) participantes, ou seja, 50\% justificaram suas notas identificando exatamente o erro cometido pelo educando. Uma das justificativas dadas de forma coerente foi a do participante $\mathrm{P} 2$ ao expressar que,

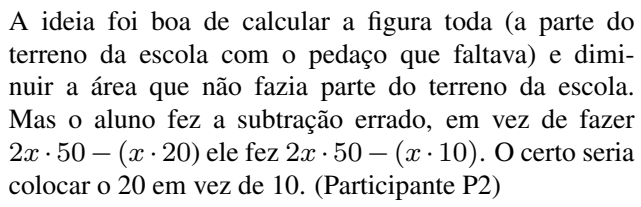

Já, outros 04 (quatro) participantes, que equivale a $33,33 \%$ em suas justificativas não fizeram uma explicação plausível sobre o principal erro cometido pelo educando na questão, e usaram argumentos que se distanciam desse erro. E dentre essas justificativas destacamos a do participante P9, onde o mesmo argumentou que "o aluno demonstrou não ter noção em cálculos de áreas"(P9).

Outros 02 (dois) participantes, que equivale a $16,67 \%$ distanciaram-se um pouco em suas justificativas sobre o erro cometido pelo educando, porém não por completo, apenas parcialmente, como na justificativa do participante P12, ao argumentar que "o aluno tem conhecimento de figuras planas, porém não desenvolve o cálculo corretamente"(P12).

Assim, podemos perceber que esse participante não deixa explicito em sua justificativa o principal erro do educando, que foi colocar $10 \mathrm{em}$ vez de $20 \mathrm{em}$ sua resolução, mas esse participante declara que o educando conhece figuras planas, o que de fato é verídico.

$\mathrm{Na}$ questão 2, ao calcularmos o $\mathrm{CV}$ entre as notas dadas, obtivemos um percentual igual a $81,63 \%$ indicando também uma alta variabilidade das notas dadas pelos participantes da pesquisa.

\subsection{Análise da Questão 3}

Já esta questão apresentava o seguinte problema: Uma criança está brincando de fazer triângulos com palitos de fósforos como mostra o desenho a seguir (Figura 3 .
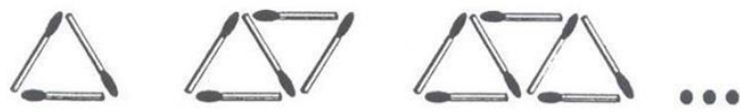

Figura 3: Sequência de triângulos com palitos.

Observando a sequência de triângulos feita pela criança, (Figura 3) complete a tabela com os dados referentes a esta sequência, e responda quantos palitos seriam necessários para fazer 10 triângulos? 


\begin{tabular}{|c|c|c|c|c|c|c|}
\hline $\begin{array}{c}\text { Número } \\
\text { de } \\
\text { triângulos }\end{array}$ & 1 & 2 & 3 & 4 & 5 & $n$ \\
\hline $\begin{array}{c}\text { Quantidade } \\
\text { de } \\
\text { palitos }\end{array}$ & 3 & 5 & 7 & 9 & 11 & $n+2$ \\
\hline
\end{tabular}

Figura 4: Resposta do aluno.

Esta questão apresenta um maior grau de dificuldade, pois tem como objetivo encontrar a regularidade da sequência apresentada e representar de forma algébrica o número de palitos para dez triângulos. E como em todas as outras questões, esta também contém um erro construtivo feito de forma proposital, com o intuito de saber como que os bolsistas do PIBID fariam essa avaliação, aplicando uma nota e justificando-as.

Nessa questão na qual o aluno deveria identificar a regularidade existente em uma sequência, generalizá-la e, por fim, representá-la algebricamente, nove (09) dos participantes, ou seja, $75 \%$ identificaram e justificaram exatamente o erro cometido. Dessas justificativas, destacamos a do participante P11, onde ele alegou que " $o$ aluno acertou a razão da sequência, porém errou na fórmula que foi $n+2$, onde o certo seria $2 n+1$ "(P11).

Mesmo essa questão apresentando um grau de abstração maior, tivemos apenas um (01) participante, o $\mathrm{P} 4$, que equivalente a $8,33 \%$ que não justificou de forma coerente com o erro do educando. Na justificativa dada pelo participante $\mathrm{P} 4$, ao afirmar que "o aluno não compreendeu o conceito da sequência"( $\mathrm{P} 4)$, podemos observar que essa justificativa não condiz com a resposta do educando, pois o aluno consegue perceber que existe uma razão nessa sequência, não conseguindo apenas estabelecer uma expressão que correspondesse ao $10^{\circ}$ elemento.

Apenas 02 (dois) dos participantes, que corresponde a $16,67 \%$ encontraram o erro cometido, mas em suas justificativas não foram objetivos e desviaram um pouco do que realmente se tratava o erro. Como podemos observar na justificativa dada pelo participante P8, ao argumentar que "o aluno constatou algo obvio o que não quer dizer correto, mas encontrou estratégia" (P8), ou seja, não faz um argumento claro sobre onde o educando cometeu o erro, e fala apenas que esse educando encontrou alguma estratégia.

O CV entre as notas dadas na questão 3 é de 47,67\% que também indica uma variabilidade elevada das notas dadas pelos participantes da pesquisa.

\subsection{Análise da Questão 4}

A quarta questão também dispõe de um ótimo problema, que diz o seguinte: Um projétil é lançado do solo obliquamente descrevendo uma curva de equação $y=200 x-4 x^{2}$, e que $x$ e $y$ são dados em metros. Qual a altura máxima do lançamento?

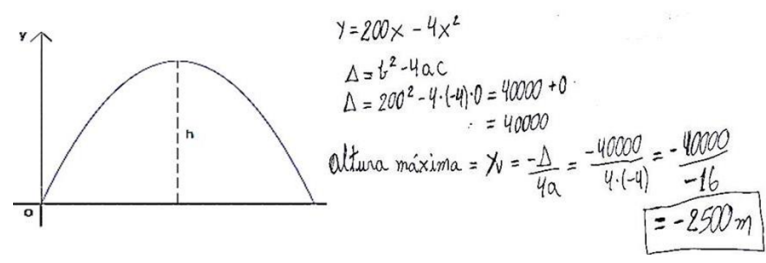

Figura 5: Resposta do aluno.

O objetivo dessa questão é muito claro, encontrar a altura máxima, e para isso basta saber calcular o ponto de máximo da parábola que é o Yv. E o erro construtivo que criamos foi apenas de um sinal na solução final, coisa que já havia sido trabalhado no inicio da resolução, com o intuito de provocar nos bolsistas uma reflexão na hora de avaliar, pois na resolução o educando demonstrou que sabe trabalhar o jogo de sinal.

E nessa questão, 09 (nove) participantes, correspondente a $75 \%$ em suas avaliações justificaram exatamente o erro apresentado pelo educando, tal questão exigia do educando alguns conceitos bem formalizados para poder solucionar o problema.

Dentre as justificativas dadas para essa questão, ressaltamos a do participante P7, onde expressou que,

\footnotetext{
O aluno demonstrou toda a capacidade em resolver questões que envolvem ponto de máximo (ou mínimo), acertando tudo até o momento em que deveria concluir, onde cometeu um deslize, porém, acredito que ele simplesmente se confundiu no momento da finalização, pois ele já havia feito um jogo de sinal anteriormente e respondeu corretamente. $\mathrm{O}$ erro cometido, não se caracteriza como falta de conhecimento, devido ele já ter passado por um jogo de sinal e ter respondido correspondente. (Participante $\mathrm{P7}$ )
}

Outros 03 (três) participantes, que corresponde a $25 \%$ desses participantes, justificaram a resolução do educando apenas parcialmente coerente com o erro encontrado, como observamos na justificativa dada por $\mathrm{P} 1$, ao argumentar que "o aluno soube resolver adequadamente errando apenas o sinal no fim do enunciado, demonstrando que não sabe as operações com sinais" (P1). No entanto, P1 não observou que esse educando já havia trabalhado com sinais nessa mesma questão, e corretamente.

Como podemos observar, nenhum participante justificou a resolução dessa questão de forma totalmente incoerente.

Nessa questão 2, o CV entre as notas dadas, é de $13,95 \%$ indicando assim uma baixa variabilidade das 
notas dadas pelos participantes da pesquisa.

\subsection{Análise da Questão 5}

Na ultima questão, o problema apresentado é bem mais complexo, e diz o seguinte: Se João correr a uma velocidade de $30,0 \mathrm{~km} / \mathrm{h}$, ele completa uma certa distância em 6 minutos. Se em 8 minutos, ele correr essa mesma distância, qual será sua velocidade?

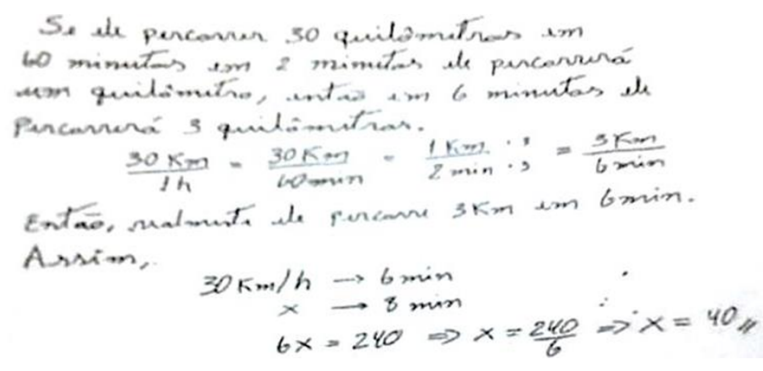

Figura 6: Reposta do aluno.

O objetivo dessa questão é encontrar a velocidade dentro do tempo de oito minutos considerando a mesma distância feita em seis minutos, o que o caracteriza como uma questão sobre regra de três inversamente proporcional. E o erro construtivo cometido propositalmente, e dá pelo fato da resposta dada ter sido feita como uma regra de três diretamente proporcional, encontrando uma velocidade maior.

O intuito desse erro é causar uma reflexão nos bolsistas na hora de avaliar, pois o raciocínio representado na resolução é de um educando que tem um conhecimento a respeito do assunto, errou por um simples descuido e falta de atenção.

E apenas 04 (quatro) dos participantes, o equivalente a $33,33 \%$ justificaram o erro do educando corretamente, sendo coerente com a resolução e o erro encontrado. Destacamos aqui a justificativa dada por P10, onde o mesmo argumentou que,

\begin{abstract}
Para resolução da questão bastava a segunda parte da re solução. Embora ele tenha percebido que se tratava de uma regra de três, não percebeu que se tratava de uma inversamente proporcional, não percebeu que a distância era a mesma e o tempo para percorrer aumentou, logo percorreu mais devagar e o valor que ele encontrou é maior (40>30). Isso modificou totalmente o resultado. E a questão tratava especificamente de uma inversamente proporcional e o aluno não absorveu isso. (Participante P10)
\end{abstract}

E de forma bastante considerável 05 (cinco) participantes que corresponde a $41,67 \%$ que fizeram suas avaliações e justificativas, não tiveram coerência com a resolução dada pelo educando, e seus argumentos não condizem com a possível resolução correta que o educando deveria ter chegado.

Uma dessas justificativas foi a do participante P2, quando expressou que "o aluno não coloca os valores na mesma unidade de medida"(P2). Mas, essa afirmação não condiz com um argumento correto para uma resposta certa, pois não é possível colocar os valores dados na mesma unidade de medida, e o erro do educando foi mesmo de não perceber que se tratava de uma regra de três inversamente proporcional.

Outros 03 (três) participantes, o equivalente a $25 \%$ encontraram o erro cometido pelo educando, mas ao justificarem não foram precisos em seus argumentos, ou seja, deixaram a desejar, como vemos na justificativa dada por P4, ao argumentar apenas que "a velocidade percorrida era para ser menor que $30 \mathrm{~km} / \mathrm{h}$ ”(P4), não descrevendo exatamente onde foi que o educando cometeu seu erro.

Na quinta e ultima questão, o CV entre as notas dadas, é de 66,70\% indicando que também houve uma alta variabilidade das notas dadas pelos participantes da pesquisa.

\section{CONSIDERAÇÕES FINAIS}

Neste trabalho objetivamos responder à seguinte questão de pesquisa: Como e em que medida o erro do educando pode ser aproveitado na construção de sua aprendizagem matemática na concepção dos futuros professores? E com base na pesquisa que realizamos e na análise do teste, foi possível termos uma ideia mais consistente de como pensam os futuros professores pesquisados, em relação as suas concepções de avaliação considerando o erro do educando.

As concepções por parte dos bolsistas, futuros professores de Matemática, em relação aos erros cometidos pelos educandos, quando detectados e de forma correta, até que são bem avaliados, pois a grande maioria fizeram suas correções considerando todos os cálculos desenvolvidos pelo educando e não apenas o resultado final. Entretanto, as notas dadas pouco representaram as boas avaliações e argumentos feitos, pois em um simples erro construtivo encontrado, houve uma baixa desproporcional na nota aplicada, o que não condiz com os conceitos já formulados pelo educando muitas vezes bem explícitos na resolução.

Avaliar não é uma tarefa simples, requer muitos critérios e talvez por saberem disso, $60 \%$ dos bolsistas disseram não se sentirem preparados para avaliarem seus educandos, mesmo com as habilidades, competências e um conjunto de concepções adquiridas ao longo de suas formações o favorecem para fazerem avaliações coerentes com a aprendizagem do educando. 
Sobre o teste aplicado, observamos uma grande variabilidade na pontuação dada em cada questão pelos participantes da pesquisa sendo a $1^{\mathrm{a}}$ a $2^{\mathrm{a}}$ e a $5^{\mathrm{a}}$ as que tiveram maior índice de variabilidade, respectivamente $80,13 \%, 81,63 \%, 66,70 \%$. Isso indica que o ato de avaliar não é tarefa fácil por ser subjetiva, pois cada participante deu nota diferente e pontuando diferentemente.

Em relação à questão da coerência entre as percepções de avaliação, ensino, aprendizagem e erro, percebemos que existem divergências entre o discurso e a prática de avaliar e que nem sempre os sujeitos conseguiram identificar o erro construtivo colocado em cada questão.

Entendemos que a maturação sobre as concepções de avaliação e erro são oportunizadas pela reflexão sobre a prática, inicialmente materializada no contexto da atuação no PIBID, mas elevada na apreensão da profissão docente no contexto da práxis. Para nós o educando deve ser um sujeito ativo que formula problemas, faz conjecturas e tira conclusões diante dos desafios que lhes são propostos, é essencial que o professor tenha um olhar mais especial para o erro construtivo cometido pelo educando, que cumpra de fato um papel positivo na aprendizagem e que seja bem observado e avaliado pelo professor.

Nesse sentido, esperamos que esse trabalho possa contribuir para discussões mais aprofundados sobre as dificuldades de se avaliar devido a coexistência de diferentes concepções na prática docente e como o erro pode ser melhor percebido como parte do processo de Ensinar e Aprender por futuros professores de Matemática.

\section{REFERÊNCIAS}

ANASTASIOU, L. das G. C. Ensinar, aprender, apreender e processos de ensinagem. In: ANASTASIOU, L. das G. C.; ALVES, L. P. (Ed.). Processos de ensinagem na universidade. Joinville: Editora Univille, 2003.

BRASIL. Parâmetros curriculares nacionais do ensino médio: matemática. Brasília: Secretaria de Educação Fundamental, MEC/SEMTEC, 1997.

DEPREBITERIS, L. O desafio da avaliação da aprendizagem: dos fundamentos e uma proposta inovadora. São Paulo: EPU, 1989.

FERREIRA, I. G.; MENDONçA, L. de O. S. Concepções de avaliação e tratamento do erro no processo de ensino aprendizagem de matemática por bolsistas PIBID. 2015. Monografia (Licenciatura em
Matemática), Instituto Federal de Educação, Ciência e Tecnologia do Ceará, Canindé, 28 f.

GARNICA, A. V. M. Um ensaio sobre as concepções de professores de matemática: possibilidades metodológicas e um exercício de pesquisa. Educação $e$ pesquisa, SciELO Brasil, v. 34, n. 3, p. 495-510, 2008.

GONÇALVES, A. L.; LARCHERT, J. M. Avaliação da Aprendizagem. 1. ed. Ilhéus: EDITUS, 2011. 100 p.

HOFFMAN, J. Avaliação: mito \& desafio: uma perspectiva construtiva. 10. ed. Porto Alegre: Educação e Realidade, 1993.

Avaliação: mito \& desafio: uma perspectiva construtiva. 43. ed. Porto Alegre: Mediação, 2013.

LUCKESI, C. C. Avaliação da aprendizagem escolar. São Paulo: Cortez, 1998.

LÜDKE, M.; ANDRÉ, M. E. D. A. Pesquisa em Educação: Abordagens qualitativas. 2. ed. Rio de Janeiro: E. P. U., 2013.

PERRENOUD, P. A avaliação no espírito da excelência e do êxito escolares. Porto Alegre: Artes Médicas Sul, 1999.

Dez novas competências para ensinar. Porto Alegre: Artmed, 2000.

PINTO, N. B. O erro como estratégia didática: Estudo do erro no ensino da Matemática elementar. Campinas: Papirus, 2000.

ROMANO, E. P. O erro e a correção numa perspectiva construtivista-interacionista do ensino e da aprendizagem. Dissertação (Mestrado) — UNICAMP, Campinas, 1994.

SPERAFICO, Y. L. S.; GOLBERT, C. S. Refletindo sobre os erros na resolução de problemas envolvendo equações algébricas do $1^{\mathrm{a}}$ grau: uma experiência com alunos do ensino fundamental. In: Anais X Congresso Nacional de Educação e I Seminário Internacional de Representações Sociais, Subjetividade e Educação. Curitiba: , 2011. 